\title{
Application of manures to mitigate the harmful effects of electrokinetic remediation of heavy metals on soil microbial properties in polluted soils
}

Iman Tahmasbian $^{1 *}$, Ali Akbar Safari Sinegani², Thi Thu Nhan Nguyen ${ }^{3}$, Rongxiao Che ${ }^{1}$, Thuc D. Phan ${ }^{4}$, Shahla Hosseini Bai ${ }^{1,3}$

${ }^{1}$ Environmental Future Research Institute, Griffith University, Nathan, QLD, 4111, Australia

${ }^{2}$ Department of Soil Science, Bu-Ali Sina University, Hamadan, Iran

${ }^{3}$ Genecology, School of Science, Health, Education and Engineering, University of the Sunshine Coast. Maroochydore DC, QLD 4558, Australia

${ }^{4}$ Australian River Institute, Griffith School of Environment, Griffith University, Nathan, QLD,4111, Australia *Corresponding author.

Email address: iman.tahmasbian@griffithuni.edu.au

Tel: +61487272292 


\begin{abstract}
Ethylenediaminetetraacetic acid (EDTA) used with electrokinetic (EK) to remediate heavy metal polluted soils is a toxic chelate for soil microorganisms. Therefore, this study aimed to evaluate the effects of alternative organic chelates to EDTA on improving microbial properties of a heavy metal polluted soil subjected to EK. Cow manure extract (CME), poultry manure extract (PME), and EDTA were applied to a lead (Pb) and zinc (Zn)-polluted calcareous soil which were subjected to two electric intensities $(1.1$ and $3.3 \mathrm{v} / \mathrm{cm})$. Soil carbon pools, microbial activity, microbial abundance (e.g. fungal, actinomycetes and bacterial abundances) and diethylenetriaminepentaacetic acid (DTPA)-extractable $\mathrm{Pb}$ and $\mathrm{Zn}$ (available forms) were assessed in both cathodic and anodic soils. Applying the EK to soil decreased all the microbial variables in the cathodic and anodic soils in the absence or presence of chelates. Both CME and PME applied with two electric intensities decreased the negative effect of EK on soil microbial variables. The lowest values of soil microbial variables were observed when EK was combined with EDTA. The following order was observed in values of soil microbial variables after treating with EK and chelates: EK + CME or EK + PME > EK > EK + EDTA. The CME and PME could increase the concentrations of available $\mathrm{Pb}$ and $\mathrm{Zn}$, although the increase was less than that of EDTA. Overall, despite increasing soil available $\mathrm{Pb}$ and $\mathrm{Zn}$, the combination of EK with manures (CME or PME) mitigated the negative effects of using EK on soil microbial properties. This study suggested that the synthetic chelates such as EDTA could be replaced with manures to alleviate the environmental risks of EK application.
\end{abstract}

Keywords: Chelating agents, decontamination, EDTA, EK, electric fields, lead, microorganisms, zinc

\title{
1 Introduction
}

Soil heavy metal pollutions have become a severe problem in many parts of the world (Cui et al. 2017; Facchinelli et al. 2001; Kovacs and Szemmelveisz 2017; Li et al. 2014; Tahmasbian et al. 2014). In response, various remediation techniques have been developed to decontaminate the heavy metal polluted soils (Chen et al. 2015; Lu et al. 2014; Qiao et al. 2017; Radu et al. 2015). Electrokinetic remediation (EK) is a newly developed method and has shown to successfully remediate heavy metal polluted soils (Chirakkara et al. 2015; Dong et al. 2013; Falciglia et al. 2017; Giannis et al. 2010; Mu'azu et al. 2016). In this method, direct electric current is applied into soil leading to the migration of soil solutions, ions and colloids, through different mechanisms including electroosmosis, electromigration and electrophoresis (Acar and Alshawabkeh 1993; Safari Sinegani et al. 2015). 
To enhance the efficiency of the EK, chelates are also applied in the contaminated soils (chelate-enhanced electrokinetic) to minimise the precipitation of heavy metals at the cathode and enhance the solubility of heavy metals (Alcántara et al. 2012; Falciglia et al. 2017; Giannis et al. 2009; Yeung et al. 1996; Yoo et al. 2015). Ethylenediaminetetraacetic acid (EDTA) is one of the most used chelates applied with EK for the remediation of heavy metals (Alcántara et al. 2012; Dasgupta et al. 2016; Dong et al. 2013; Ryu et al. 2017; Song et al. 2016; Zhang et al. 2014). Although the application of chelates with EK has been reported to improve the EK efficiency, both the EK and chelates have shown to negatively influence soil biochemical properties (Alkorta et al. 2004; Baek et al. 2009; Epelde et al. 2008; Safari Sinegani et al. 2015).

The EK has been shown to decrease soil microbial biomass carbon (MBC), microbial activity and abundance possibly due to the toxic effects of released heavy metals and/or soil pH alteration (Cang et al. 2012; Choi et al. 2013; Guo et al. 2014; Li et al. 2010; Li et al. 2015; Tahmasbian and Nasrazadani 2012; Wang et al. 2013). However, a study reported an increased MBC in a pot experiment following EK treatment due to the release of the organic substrate (Cang et al. 2012). A stimulation of soil respiration (SR) next to anode has been also observed due to increased nutrient availability and enhanced microbial attempt to maintain their intercellular $\mathrm{pH}$ (Lear et al. 2004). EDTA has shown to reduce soil microbial activity, MBC and abundance due to the toxicity of EDTA and increased heavy metal availability and solubility (Lee and Sung 2014; Mühlbachová 2011; Pramanik and Kim 2013; Tahmasbian Ghahfarokhi 2012; Usman et al. 2013). Hence, combining the EK with EDTA can intensify the detrimental effects of EK on soil microbial properties (Kim et al. 2010; Tahmasbian Ghahfarokhi 2012). Therefore, it is necessary to replace EDTA with chelates, that are more environmentally friendly, to mitigate the negative effects of EK on soil biochemical properties.

The alternative chelates are required to increase the availability of heavy metals in soils to enhance EK efficiency with less negative effects on soil microbial properties. Manures have been frequently reported to increase the availability of heavy metals in soil (Almås et al. 1999; de la Fuente et al. 2011; Indoria et al. 2013; Safari Sinegani et al. 2016; Safari Singani and Ahmadi 2012; Wu et al. 2012). Manures were also reported to improve soil microbial properties through increasing the organic substrate and soil physiochemical conditions (Elzobair et al. 2016; Pu et al. 2017; Usman et al. 2013; Zhang et al. 2017). Our complementary studies have also shown that the combination of manures and EK (manure-enhanced EK) increased the diethylenetriaminepentaacetic acid (DTPA)-extractable (available) form of heavy metals in the contaminated soils (Safari Sinegani et al. 2015; Tahmasbian Ghahfarokhi 2012; Tahmasbian and Safari Sinegani 2014). However, effects of the application of 
manure-enhanced EK on soil microbial properties remain uncertain. Therefore, this study aimed to evaluate the effects of manure-enhanced EK on soil microbial properties as alternatives to EDTA-enhanced EK.

\section{Materials and methods}

\subsection{Pot establishment, treatments and experimental design}

Soil used in this pot trial was collected from the top $20 \mathrm{~cm}$ of a pasture located in the vicinity of a lead (Pb) and zinc $(\mathrm{Zn})$ mine in Hamadan province $\left(34^{\circ} 10^{\prime} 18.59^{\prime \prime} \mathrm{N}, 48^{\circ} 59^{\prime} 49.34^{\prime \prime} \mathrm{E}\right)$, west Iran in 2012 . The characteristics of the soil are shown in Table 1 . The soil was sieved $(2 \mathrm{~mm})$ prior to pot establishment and $7 \mathrm{~kg}$ of the soil was placed in plastic pots $(20 \mathrm{~cm}$ height and $11 \mathrm{~cm}$ radius $)$. A graphite electrode $(1 \mathrm{~cm} \times 1 \mathrm{~cm} \times 15 \mathrm{~cm})$ was inserted in the centre of the pot as cathode with four electrodes inserted around the pot as anodes. Therefore, a centreoriented multiple-anode-electrode system was applied in each pot using graphite electrodes to create homogeneous electric fields in the whole pot (Fig. 1) (Tahmasbian and Safari Sinegani 2013). A cylindrical galvanised iron mesh (20 cm height and $5.5 \mathrm{~cm}$ internal radius) was placed in each pot to divide the soil into cathodic and anodic sections enabling us to study and explain the effects of treatments in each cathodic and anodic soil separately (Fig. 1).

The chelates used in this experiment included EDTA as the most commonly used chelate as well as cow manure extract (CME), and poultry manure extract (PME) to be assessed as alternatives to EDTA. All the chelates were sterilised in an autoclave at $121^{\circ} \mathrm{C}$ for $20 \mathrm{~min}$ and applied to the soils at a rate of $2 \mathrm{~g} \mathrm{~kg}^{-1}$ dry soil 30 days following the pot establishment (Tahmasbian and Safari Sinegani 2013). Fresh manures were collected from a local farm and added to deionized water (1:5 ratio) and the suspension was shaken at $120 \mathrm{rpm}$ for 20 min. The suspension then centrifuged at $4000 \mathrm{rpm}$ for $10 \mathrm{~min}$. The solution was then filtered before applying to the soil. The properties of the CME and PME have been summarised in Table 1.

The EK was applied with two intensities including $1.1 \mathrm{~V} / \mathrm{cm}$ and $3.3 \mathrm{~V} / \mathrm{cm}$ (Safari Sinegani et al. 2015). Intensities of electric fields were chosen to be within the range of other studies (Cang et al. 2009; Jackman et al. 1999; Li et al. 2010; Tahmasbian and Safari Sinegani 2014, 2016). Each pot received either $1.1 \mathrm{~V} / \mathrm{cm}$ or $3.3 \mathrm{~V} / \mathrm{cm}, 14$ days after the chelates application to the soil, $1 \mathrm{~h} \mathrm{day}^{-1}$ for 14 contiguous days (Lim et al. 2004; Tahmasbian and Safari Sinegani 2013, 2014). The control soil received only electricity (either $1.1 \mathrm{~V} / \mathrm{cm}$ or $3.3 \mathrm{~V} / \mathrm{cm}$ ). The pots were watered during the whole period of the experiment, and soils were kept at approximately $80 \%$ field capacity. The 
experiment was a complete randomised design with three replicates. The pots were randomly placed in a temperature controlled glasshouse at a consistent temperature varied between $22^{\circ} \mathrm{C}$ and $25^{\circ} \mathrm{C}$.

\subsection{Sample collection and analyses}

At the end of the experiment, 58 days following the pot establishment, fresh soil samples were carefully removed from inside and outside of the meshes and labelled as cathodic and anodic soils, respectively. The samples were placed in ziplock plastic bags and stored at $4^{\circ} \mathrm{C}$. All the microbial analyses were conducted within two weeks following the sample collection.

Soil total organic carbon (TOC) was measured using Walkley and Black procedure (Walkley and Black 1934). To measure soil MBC, two $10 \mathrm{~g}$ sub-samples of fresh soil at each replicate were weighed; one of the sub-samples was fumigated by chloroform for $24 \mathrm{~h}$. All fumigated and non-fumigated sub-samples were added $50 \mathrm{ml}$ of $0.5 \mathrm{M}$ $\mathrm{K}_{2} \mathrm{SO}_{4}$ and were shaken with an end-over-end shaker for $30 \mathrm{~min}$, followed by filtering through a Whatman 42 filter paper. The total organic carbon of both extractions was measured using Walkley and Black method (Walkley and Black 1934). The MBC were derived as described by Vance et al. (1987). Soil respiration (SR) was assessed using sodium hydroxide $(\mathrm{NaOH})$ trap method. The fresh soil (25 g) was incubated in a sealed plastic container (1 l) at $22^{\circ} \mathrm{C}$ for seven days. The carbon dioxide $\left(\mathrm{CO}_{2}\right)$ produced by soil respiration was trapped in $10 \mathrm{ml}$ of $0.1 \mathrm{M}$ $\mathrm{NaOH}$. The remaining $\mathrm{NaOH}$ was then titrated using $0.05 \mathrm{M} \mathrm{HCl}$ (Hosseini Bai et al. 2012).

Soil fungal abundance (FA), actinomycetes abundance (AA) and bacterial abundance (BA) were evaluated using colony counting method on potato dextrose agar, rose bengal starch casein nitrate agar, and nutrient agar, respectively (Alef and Nannipieri 1995). The potato dextrose agar and nutrient agar were purchased from Merck.

Soil electrical conductivity (EC) and pH were measured in 1:5 soil-water extract (Tahmasbian and Safari Sinegani 2013). Soil available Pb and Zn were extracted by DTPA (Lindsay and Norvell 1978) and analysed by atomic absorption spectrometry on a Varian 220 instrument.

\subsection{Statistical analysis}

A three-way factorial analysis of variance (ANOVA) was performed using soil charges (cathodic and anodic), chelates (EDTA, CME and PME) and EK intensities $(1.1$ and $3.3 \mathrm{~V} / \mathrm{cm})$ as the main effects to determine the differences among the microbial variables, EC and available forms of $\mathrm{Pb}$ and $\mathrm{Zn}$ followed by Duncan’s new multiple range test. The interactions among soil charges, chelates and EK intensities in most variables were 
significant (data not presented). Therefore, a two-way ANOVA was performed to test the effects of chelates and EK treatments in each cathodic and anodic soil separately (Table 2). In each soil, when the interactions between chelate and EK were not significant, EK and chelate treatments were assessed separately using a one-way ANOVA (TOC, MBC and available Pb in the cathodic soil, BA in the cathodic and anodic soils).

It should be noted that the data of soil heavy metal concentrations including total concentration, soluble + exchangeable (sol-exch) fraction, organic-bound and carbonate-bound fractions have been extracted from our complimentary studies (Tahmasbian and Safari Sinegani 2013, 2014) to perform a correlation between soil microbial and chemical properties. The statistical analyses were conducted using SAS 9.4.

\section{Results}

\subsection{Effects of chelates and EK on cathodic soil}

The EK did not significantly affect soil TOC (Tabel 2). Soil TOC in the EDTA-treated soil also did not differ compared to control; however, CME and PME significantly increased soil TOC compared to both control and EDTA (Fig. 2a). Although MBC decreased significantly in all three chelates compared to control, it was significantly higher in CME and PME treated soils compared to EDTA (Fig. 2b). EK also significantly reduced MBC in the cathodic soil compared to control but there was no significant difference between electricity levels (Fig. 2c). The interaction between chelates and EK was not significant for MBC. The CME and PME treated soils increased the SR compared to EDTA in all the electricity levels. Increasing the intensity of the electric fields decreased the SR in all the chelate-treated soils (Fig. 3a).

In general, FA and AA were significantly higher in CME and PME treated soils than those of EDTA regardless of the electricity levels (Fig. 3c, e). BA was also significantly higher in CME and PME treated soils compared to EDTA and control, whereas EK significantly decreased BA (Fig. 4a, b). The interaction between chelates and EK was not significant for BA. The values of EC increased in all the chelates treated soils compared to control and decreased by increasing the electric intensity (Fig. 5a). The effects of chelates, EK and their interaction were significant for $\mathrm{pH}$ (Table 2). There was not an obvious trend in the variation of $\mathrm{pH}$. However, the highest $\mathrm{pH}$ was observed in EDTA combined with $3.3 \mathrm{~V} / \mathrm{cm}$ while CME reduced $\mathrm{pH}$ to its minimum in the absence of electricity (Table 3). 
The EDTA and PME significantly increased the concentrations of available Pb compared to control in cathodic soil. The differences of available $\mathrm{Pb}$ in CME treated soil were not statistically significant (Fig. 6a). EK also significantly increased available Pb compared to control but there was no significant difference between electricity levels (Fig. 6b). The interaction between EK and Chelates was not significant for available Pb. The maximum values of available $\mathrm{Zn}$ in lower electric field intensity (0 and $1.1 \mathrm{~V} / \mathrm{cm}$ ) were measured in EDTA treated soil followed by CME. In the high electric field intensity $(3.3 \mathrm{~V} / \mathrm{cm})$, however, the concentration of available $\mathrm{Zn}$ was significantly higher in PME compared to other chelates (Fig. 6c).

\subsection{Effects of chelates and EK on anodic soil}

Soil TOC was not significantly altered by chelates and EK in the anodic soil (Table 2). MBC and SR were significantly higher in CME and PME compared to EDTA and control in all the electricity levels. Increasing the electric fields intensified the decreases of MBC and SR in anodic soil (Fig. 2d; Fig. 3b).

The values of FA and AA were significantly higher in CME and PME compared to EDTA in all the electric field intensities, although increasing the electric field intensities decreased FA and AA in all chelate-treated soils (Fig. 3d, f). BA was also significantly higher in CME and PME compared with EDTA and control (Fig. 4c). The electric fields decreased the values of BA by increasing the intensity (Fig. 4d). The interaction between chelates and electric fields was not significant for BA. The EC values increased in all the chelates whereas decreased by electric treatment except in PME (Fig. 5b). The maximum values of pH were observed in EDTA and PME in the absence of electricity and the minimum value was observed in PME combine with $3.3 \mathrm{~V} / \mathrm{cm}$ (Table 3).

The highest concentration of available $\mathrm{Pb}$ was measured in the soils treated with EDTA combined with $1.1 \mathrm{~V} / \mathrm{cm}$ electricity, while in other levels of electricity EDTA did not increase the concentrations of available Pb. CME and PME significantly increased available $\mathrm{Pb}$ in the $3.3 \mathrm{~V} / \mathrm{cm}$ compared to control (Fig. 6d). There was no significant difference between the values of available $\mathrm{Pb}$ in $\mathrm{CME}$ and PME combined with $1.1 \mathrm{~V} / \mathrm{cm}$ and that of control. All the three chelates increased the available $\mathrm{Zn}$ in the presence of electricity with the maximum values in PME treated soil in $3.3 \mathrm{~V} / \mathrm{cm}$ (Fig. 6e).

\subsection{Relationship among soil biochemical properties}

In cathodic soil, microbial variables had a significant but negative correlation with the available forms and total concentrations of heavy metals. The variables were also negatively correlated to the carbonate-bound fraction of heavy metals and pH. Soil microbial variables were positively correlated to soil TOC and EC (Table 4). 
In anodic soil, microbial variables had significant, but negative, correlations with sol-exch fraction and available form of heavy metals. The correlation was positive among soil microbial variables, carbonate-bound and the total concentrations of heavy metals (Table 4).

\section{Discussion}

Our results indicated that EK combined with either CME, PME or EDTA decreased soil microbial variables in both cathodic and anodic soils. However, the magnitude of the reduction was smaller where EK applied with either CME or PME compared to that applied with EDTA which further supported our hypotheses. In summary, the following order was observed for the values of microbial variables in the treated soils: microbial variables in $\mathrm{EK}+\mathrm{CME}$ or $\mathrm{EK}+\mathrm{PME}>\mathrm{EK}>\mathrm{EK}+\mathrm{EDTA}$.

The reduction of soil microbial activity and abundance was mainly influenced by EK and EDTA in this study which was consistent with other studies (Bahemmat et al. 2015; Pramanik and Kim 2013). For example, a decrease in microbial respiration, abundance and enzyme activities after EK application has been reported due to the variation in soil pH and soil heavy metal concentrations (Bahemmat et al. 2015; Cang et al. 2012). EDTA application was also reported to decrease soil microbial activity due to the formation of EDTA-heavy metal complex (Pramanik and Kim 2013). In our study, hence, the changes in heavy metal availability can be considered as the main driving factor in soil bacterial activity and abundance after a chelate-enhanced EK treatment.

In the cathodic soil of the current study, the reduction in microbial variables might also be attributed to heavy metal availability and accumulation. EDTA, manures and EK increased the available forms of heavy metals in the current study. In general, EDTA and manures increase the sol-exch fraction and available forms of heavy metals via forming a heavy metal-chelate complex whereas EK increases the solubility of heavy metals by $\mathrm{H}^{+}$ generation at anode (Safari Sinegani et al. 2015; Sah and Che 1998; Virkutyte et al. 2002; Zhao et al. 2014). The solubilized heavy metals are then transported from anode to cathode by electroosmosis and electromigration, which increase the total concentrations of heavy metals in cathodic soil (Kim et al. 2009; Safari Sinegani et al. 2015; Virkutyte et al. 2002; Zelina and Rusling 1998). The increased available forms of heavy metals by various chelates and EK as well as heavy metal accumulation in cathodic soil have been also reported in other studies (Safari Sinegani et al. 2015; Sah and Che 1998; Virkutyte et al. 2002; Zhao et al. 2014). For example, EDTA has significantly increased the soluble form of heavy metals in soil due to the formation of heavy metal-EDTA complex (Song et al. 2016) which was consistent with the results of this study. In another study, cattle manures 
have been also shown to increase the availability of heavy metals in soil (Zhao et al. 2014). Therefore, the toxicity of the heavy metals in cathodic soil might be one of the main driving factors for the reduction of soil microbial variables which further was supported by our results in the current study.

The toxic effects of heavy metals occur when heavy metals, such as $\mathrm{Pb}$ and $\mathrm{Zn}$, bind to sulfhydryl groups in microbial cells and inhibit the activity of sensitive enzymes (Nies 1999; Wang et al. 2009). Heavy metals may also interact with physiological ions and, therefore, inhibit the function of respective physiological cations (Nies 1999; Wang et al. 2009). Heavy metals toxicity has been frequently reported to restrict soil microbial activities and abundance (Baath 1989; Feng et al. 2016; Kandeler et al. 1996; Rajapaksha et al. 2004).

A combination of EDTA toxicity and $\mathrm{pH}$ alteration by EK has also been shown in other studies to negatively decrease soil microbial variables (Bahemmat et al. 2015; Epelde et al. 2008; Kim et al. 2010; Lear et al. 2004). In the current study, we did not assess EDTA toxicity; however, we observed soil pH alteration which may have been contributed in soil microbial suppression in cathodic soil. A strong correlation has been reported between the variation in soil $\mathrm{pH}$ and microbial activity after EK treatment (Cang et al. 2009). Another study also explained that the reduction of microbial properties in the vicinity of the electrodes are due to the variations in soil $\mathrm{pH}$ (Bahemmat et al. 2015). In the current experiment, despite the fact that there was a correlation among soil pH and microbial variables in cathodic soil, the $\mathrm{pH}$ responses to specific treatments, measured at the end of the experiment, were not explicit. This might be due to the buffering capacity of calcareous soil which somewhat resulted in masking the main effects of $\mathrm{pH}$ on soil variables (Foth 1991).

In anodic soil, soil microbial reduction might also be attributed to the toxicity of heavy metals which was supported by negative correlation among microbial variables and sol-exch fraction of heavy metals (Table 4). In the current experiment, available forms of $\mathrm{Ph}$ and $\mathrm{Zn}$ were increased in anodic soil which was consistent with our complimentary study conducted using the same system (Tahmasbian and Safari Sinegani 2013). In our complimentary study, the sol-exch fraction of heavy metals increased in the anodic soil (Tahmasbian and Safari Sinegani 2013). Other studies have also reported that the concentration of soluble and available forms of heavy metals increase in anodic soils (Giannis et al. 2010; Reddy et al. 2001; Virkutyte et al. 2002). Therefore, the increase in soluble and available forms of heavy metals might be one of the main factors reducing soil microbial variables in anodic soil.

The migration of microorganisms by electrophoresis from the anodic soil to the cathodic soil may be the additional possible mechanism explaining the decrease of microbial variables in the anodic soil. The positive correlations 
among microbial variables, total and carbonate-bound heavy metals in anodic soil may suggest the simultaneous migration of microorganisms and heavy metals resulted by electrophoresis, electroosmosis, and electromigration. The possibility of microorganism migrations in soil by electrokinetic has been previously reported in other studies (Kim et al. 2005; Mena et al. 2011).

Many studies have indicated that manures and their extracts including CME and PME solubilize heavy metals leading to increase the heavy metals in the sol-exch and available forms (de la Fuente et al. 2011; Indoria et al. 2013; Zhao et al. 2014). However, the solubilizing effects of CME and PME were less than that of EDTA in the current study which was also supported by our complementary studies (Tahmasbian and Safari Sinegani 2013, 2014). Hence, the lesser heavy metal solubilisation might have been tolerated by soil microorganisms. Furthermore, organic treatments increase soil organic C and nutrients due to high organic content (Darby et al. 2016; Nguyen et al. 2017). Soil organic $C$ is the primary source of $C$ for soil microorganisms and has been reported to influence soil microbial activities (Bardgett 2005; Darby et al. 2016; Flessa et al. 2000; Hosseini Bai et al. 2015). The negative effects of increasing the toxicity of heavy metals by EK might have been offset by the stimulation effects of CME and PME on soil microbial biomass, activity and abundance. It could be suggested that EK application in the presence of manures (CME and PME) can minimise the environmental risks of EK remediation of heavy metal polluted soils.

\section{Conclusion}

The effects of using CME and PME in combination with EK on soil microbial properties were evaluated and compared with EDTA. The results showed that CME and PME could significantly reduce the negative effects of EK on soil microbial variables compared to using EK alone or in combination with EDTA. Thus, it could be suggested that EDTA can be replaced by manures such as CME and PME to mitigate the negative effects of EK remediation of heavy metal polluted soils.

\section{Acknowledgements}

The authors would like to acknowledge the Griffith University of Australia for the working environment and to gratefully acknowledge the Bu-Ali Sina University of Iran for the financial support. 


\section{Figure Captions:}

Fig. 1 The schematic image of the electrokinetic system in the pots. + and - present anode and cathode, respectively, grey arrows indicate the direction of the electric fields.

Fig. 2 Effects of chelates on total organic C (TOC) in cathodic soil (a); effects of chelates and electric fields (EK) on soil microbial biomass (MBC) in cathodic soil (b,c respectively), and the interaction of chelates and EK on MBC in anodic soil (d). Different letters show significant differences at $\mathrm{P}<0.05$.

Fig. 3 The interaction of chelates and electric fields (EK) on soil microbial respiration (SR) in cathodic and anodic soils (a, b), fungal abundance (FA) in cathodic and anodic soils (c, d) and actinomycetes abundance (AA) in cathodic and anodic soils (e, f). Different letters show significant differences at $\mathrm{P}<0.05$.

Fig. 4 The effects of chelates and electric fields (EK) on bacterial abundance (BA) in cathodic soil (a, b) and in anodic soil (c, d). Different letters show significant differences at $\mathrm{P}<0.05$.

Fig. 5 The interaction of chelates and electric fields (EK) on soil electrical conductivity (EC) in cathodic and anodic soils (a, b). Different letters show significant differences at $\mathrm{P}<0.05$.

Fig. 6 The effects of chelates and electric fields (EK) on available Pb in cathodic soil (a, b), the interaction of chelates and electric fields (EK) on available Zn in cathodic and anodic soils (c, e) and the interaction of chelates and EK on available Pb in anodic soil (d). Different letters show significant differences at $\mathrm{P}<0.05$.

Fig. 1

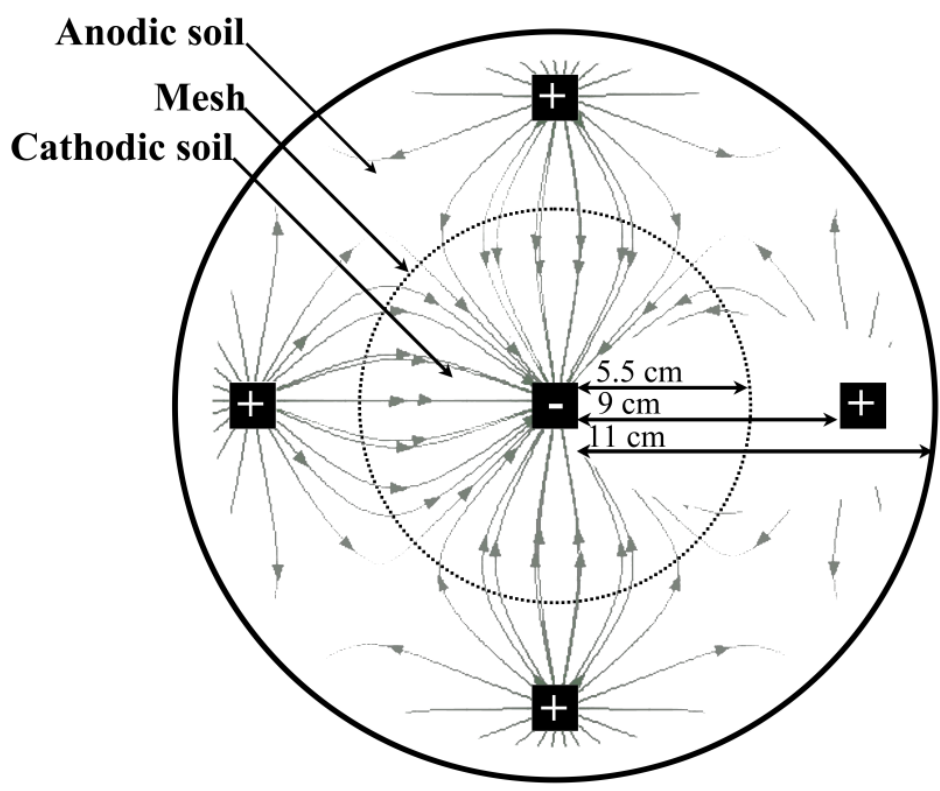


Fig. 2
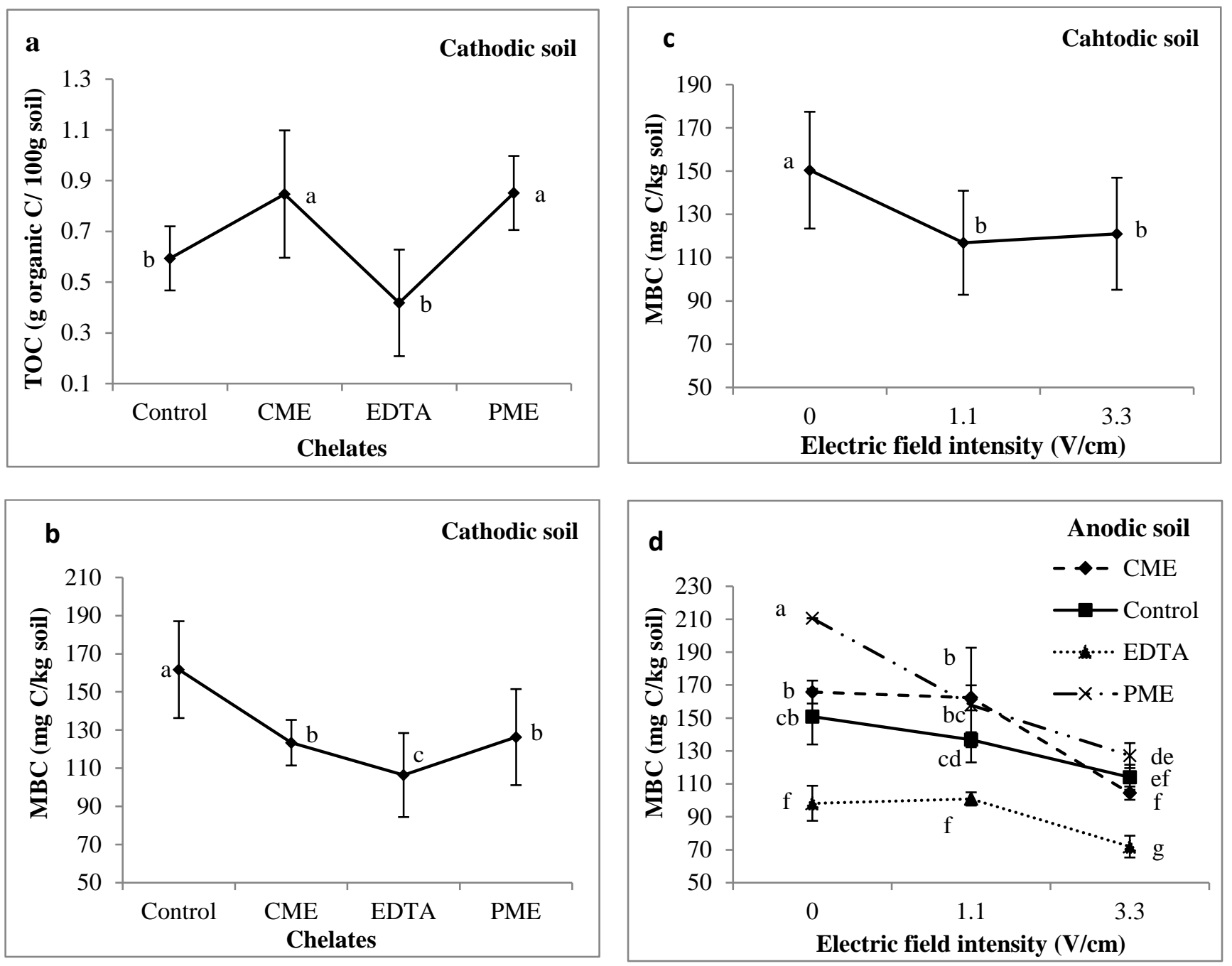
Fig. 3

$-\downarrow-\mathrm{CME}$

$\rightarrow-$ Control

….... EDTA

一. . PME
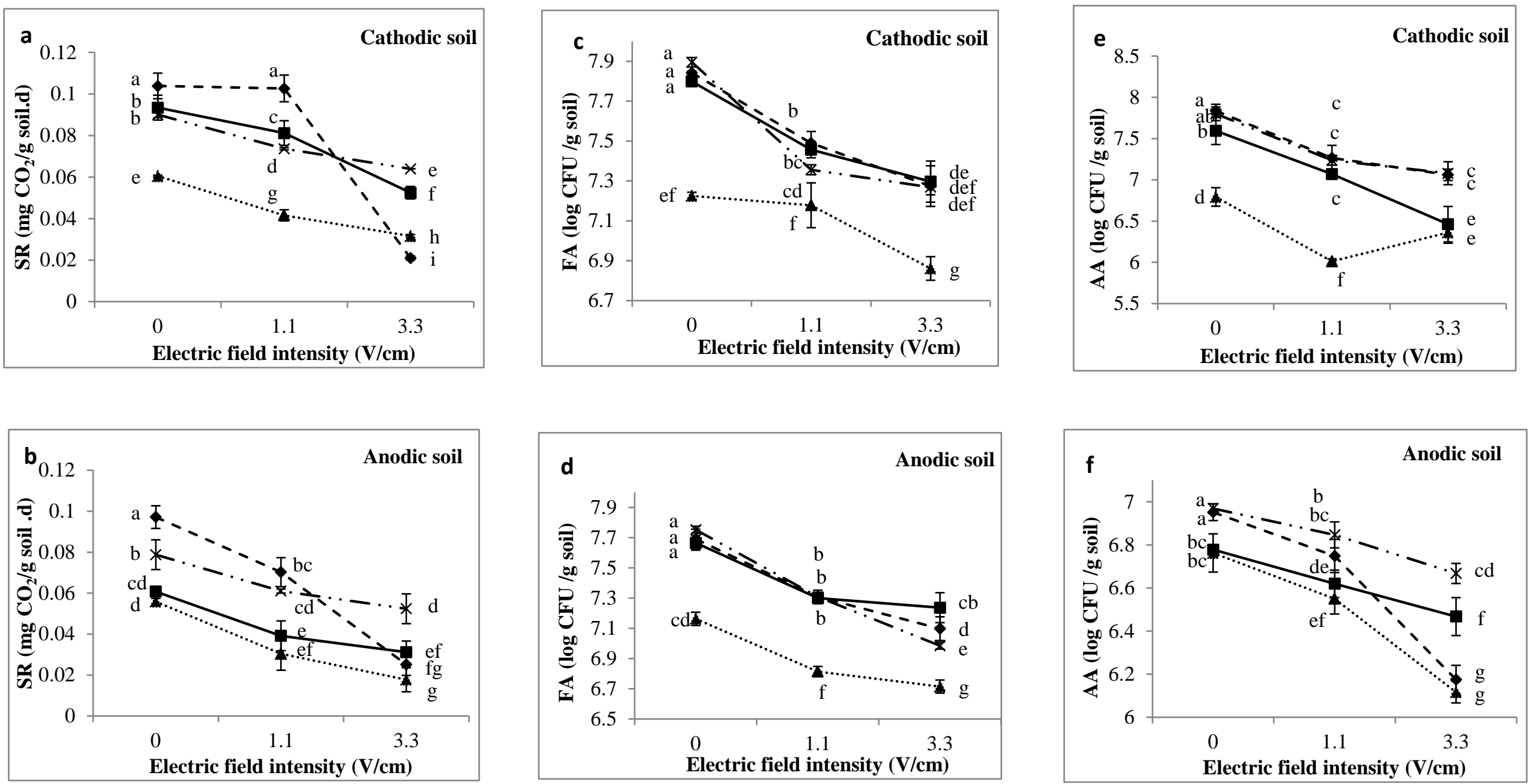
Fig. 4
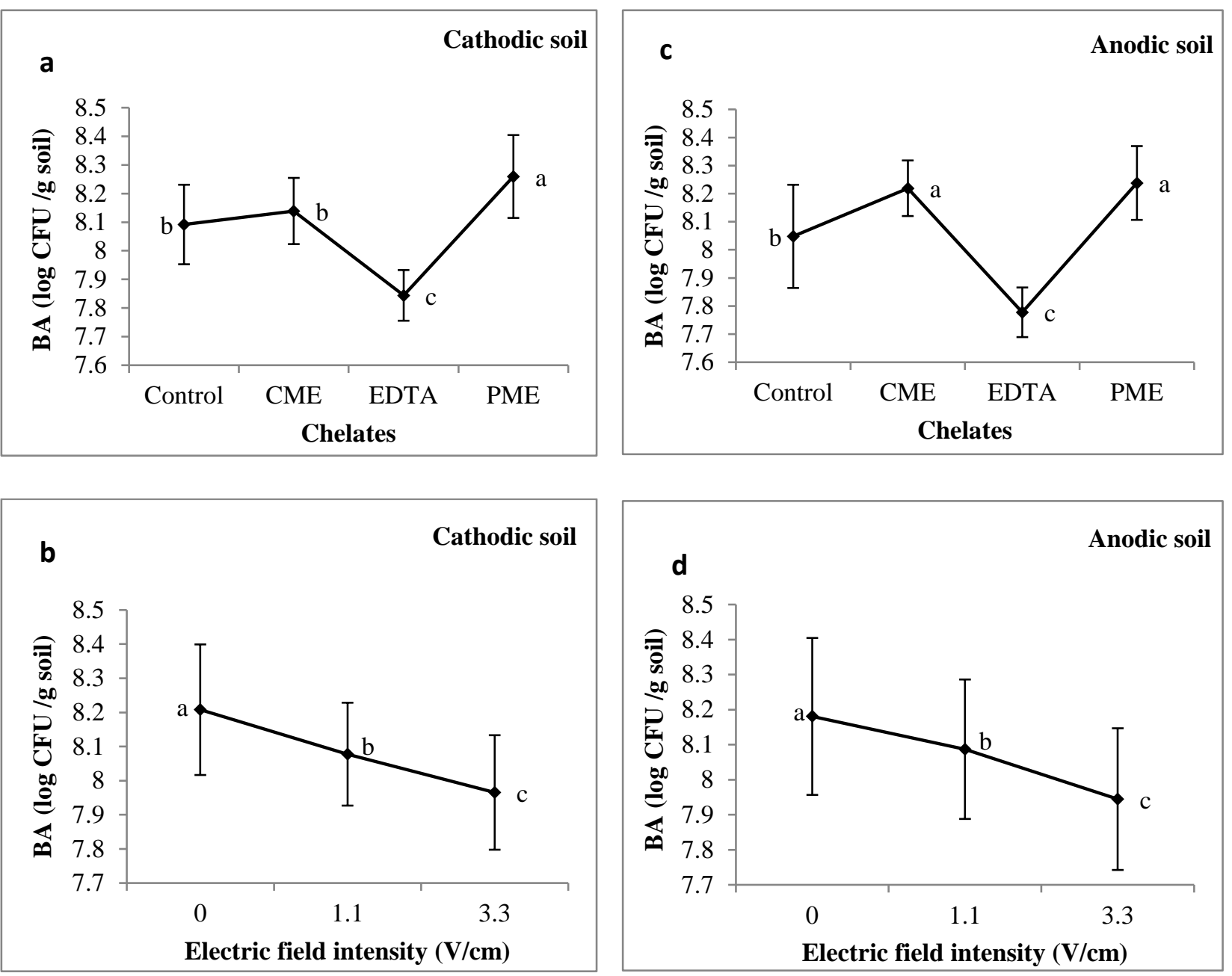
Fig. 5
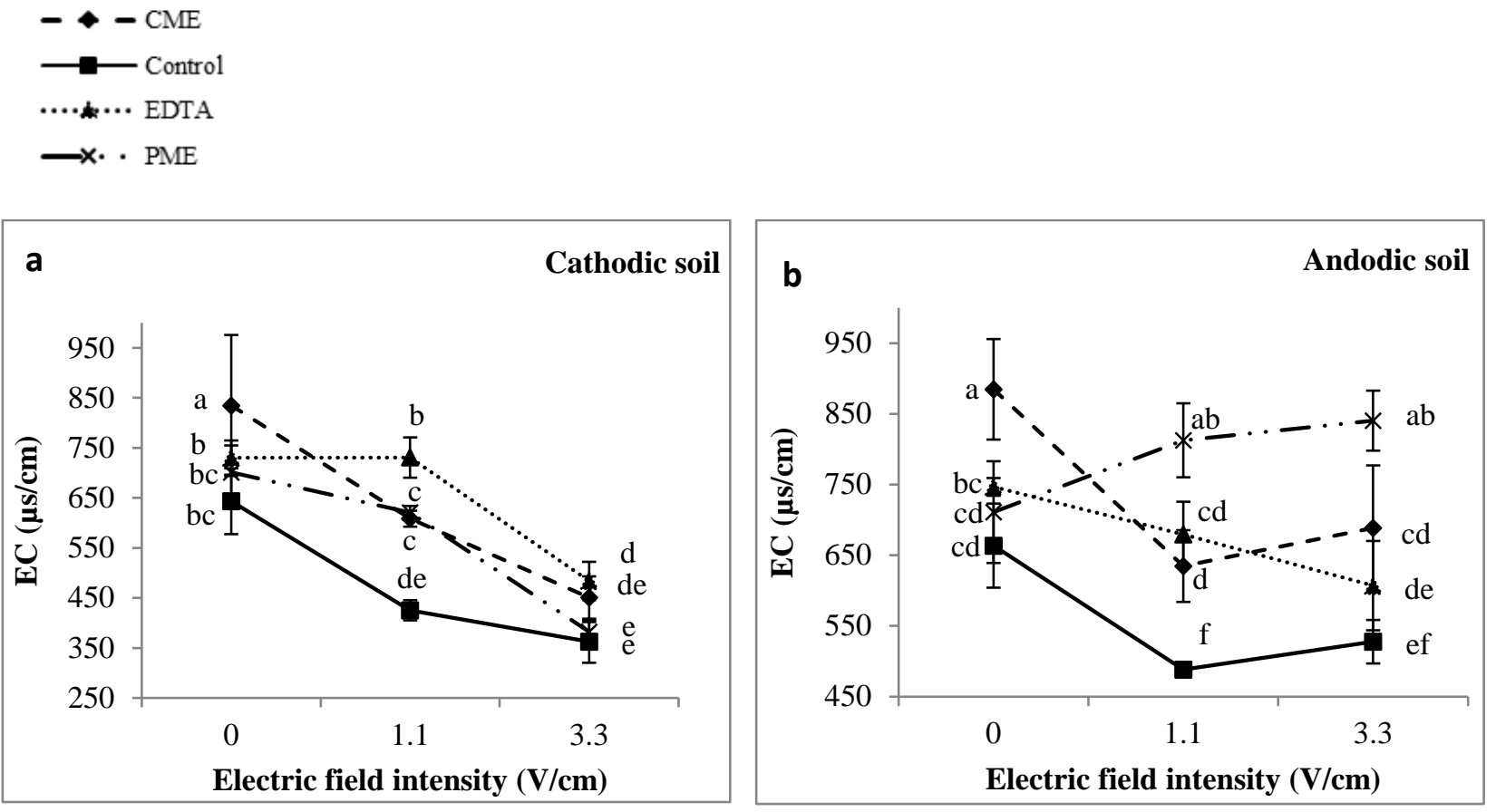
Fig. 6
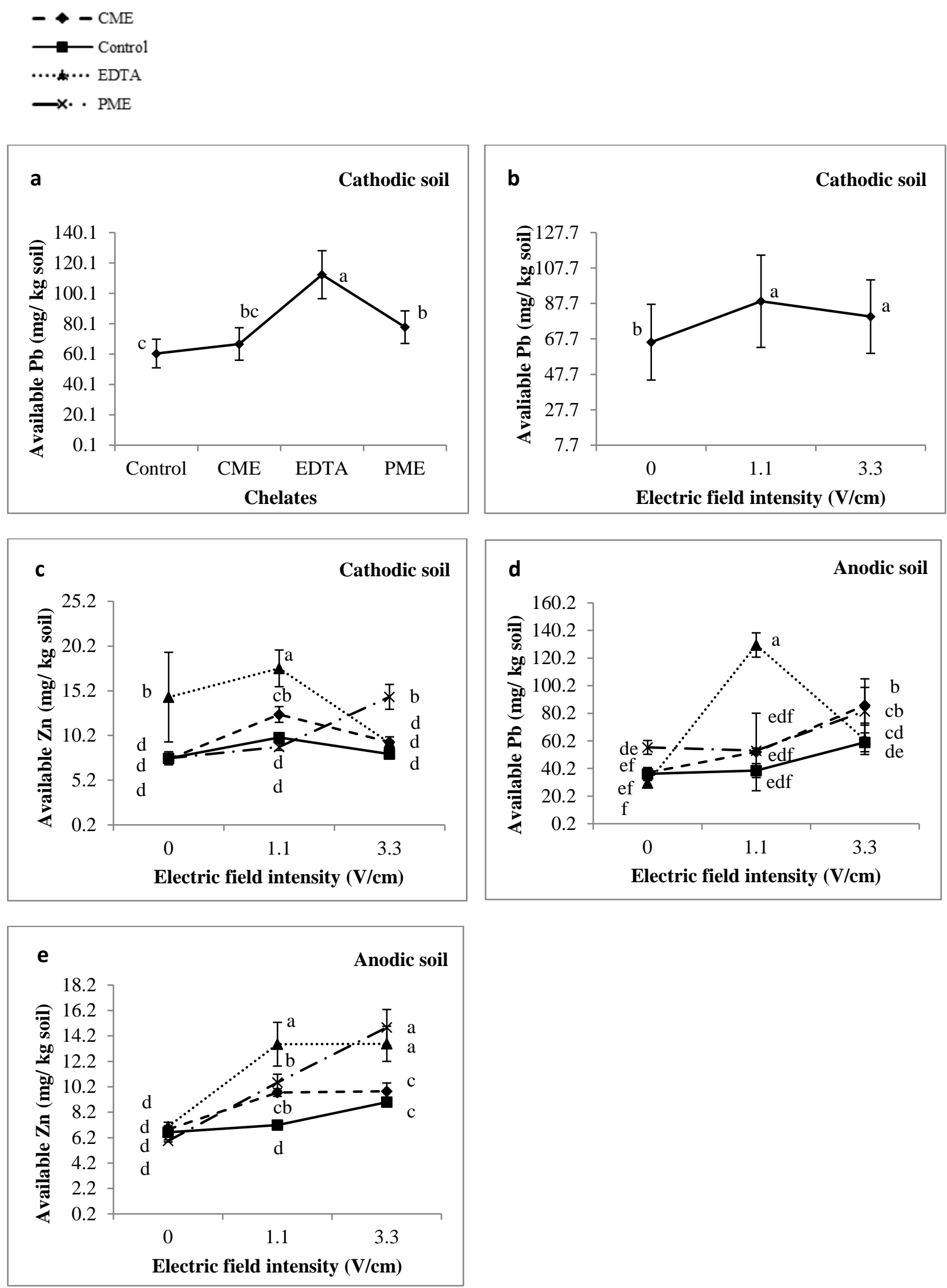
Table 1 Initial soil* and manures characteristics

\begin{tabular}{|c|c|c|c|}
\hline & Characteristics & Units & Values \\
\hline \multirow{14}{*}{$\begin{array}{l}\overline{0} \\
\bar{\omega}\end{array}$} & Texture & - & Loamy \\
\hline & pH (1:5 soil:water) & - & 7.7 \\
\hline & EC (1:5 soil:water) & $\mu \mathrm{s} \mathrm{cm}^{-1}$ & 580.65 \\
\hline & TOC & $\%$ & 0.59 \\
\hline & ECC & $\%$ & 22 \\
\hline & CEC & $\operatorname{cmol}(+) \mathrm{kg}^{-1}$ & 14.24 \\
\hline & Sol-exch Pb & $m g \mathrm{~kg}^{-1}$ & 23.33 \\
\hline & Sol-exch Zn & $\mathrm{mg} \mathrm{kg}^{-1}$ & 4.24 \\
\hline & Organic-bound $\mathrm{Pb}$ & $\mathrm{mg} \mathrm{kg}^{-1}$ & 45.43 \\
\hline & Organic-bound Zn & $\mathrm{mg} \mathrm{kg}^{-1}$ & 4.81 \\
\hline & Carbonate-bound $\mathrm{Pb}$ & $\mathrm{mg} \mathrm{kg}^{-1}$ & 621.41 \\
\hline & Carbonate-bound Zn & $\mathrm{mg} \mathrm{kg}^{-1}$ & 98.62 \\
\hline & Total Pb & $\mathrm{mg} \mathrm{kg}^{-1}$ & 1220.72 \\
\hline & Total Zn & $\mathrm{mg} \mathrm{kg}^{-1}$ & 230.8 \\
\hline \multirow{3}{*}{$\sum_{\mathcal{U}}^{1}$} & pH (1:5 soil:water) & - & 7.72 \\
\hline & EC (1:5 soil:water) & $\mu s \mathrm{~cm}^{-1}$ & 6420 \\
\hline & TDS & $\mathrm{mg} \mathrm{g}^{-1}$ & 31.33 \\
\hline \multirow{3}{*}{$\sum_{\Sigma}^{1}$} & pH (1:5 soil:water) & - & 8.20 \\
\hline & EC (1:5 soil:water) & $\mu s \mathrm{~cm}^{-1}$ & 7305 \\
\hline & TDS & $\mathrm{mg} \mathrm{g}^{-1}$ & 51.54 \\
\hline
\end{tabular}

EC electric conductivity, TOC total organic carbon;

ECC equivalent calcium carbonate

$\boldsymbol{C E} \boldsymbol{C}$ cation exchange capacity

Sol-exch Extracted by deionized water and $0.5 \mathrm{M} \mathrm{KNO}_{3}$ in $\mathrm{pH}=7$

Organic-bound Extracted by $0.5 \mathrm{M} \mathrm{NaOH}$

Carbonate-bound extracted by 0.05M EDTA

Total Extracted by $\mathrm{HNO}_{3}-\mathrm{H}_{2} \mathrm{O}_{2}-\mathrm{HCL}$

TDS Total dissolved solids

*The data extracted from Tahmasbian and Safari Sinegani (2013) and Tahmasbian Ghahfarokhi (2012). 
Table 2 Analysis of variance (mean squares) of microbial properties in cathodic and anodic soils as affected by the application of chelates and electric fields (EK)

\begin{tabular}{|c|c|c|c|c|c|c|c|c|c|c|c|c|}
\hline & & & & & & & & Mean s & & & & \\
\hline \multirow{4}{*}{ نِّ } & & $\mathrm{df}$ & TOC & $M B C$ & $S R$ & $F A$ & $A \boldsymbol{A}$ & $B A$ & $E C$ & $p H$ & $A v P b$ & AvZn \\
\hline & Electricity & 2 & 0.095 & 4013.946** & $0.006^{* *}$ & $0.773 * *$ & $1.801^{* *}$ & $0.176^{* *}$ & $285817.653^{* *}$ & $0.24^{* *}$ & $1631.862 * *$ & $26.988 * *$ \\
\hline & Chelators & 3 & $0.400 * *$ & $4848.385^{* *}$ & $0.002 * *$ & $0.374^{* *}$ & $1.727 * *$ & $0.274^{* *}$ & $54158.731^{* *}$ & $0.55^{*}$ & 4634.188** & $45.798^{* *}$ \\
\hline & Interaction & 6 & 0.004 & 176.50593 & $0.001^{* *}$ & $0.031 * *$ & $0.115^{* *}$ & 0.003 & $11481.112 * *$ & $0.29 *$ & 98.923 & $29.949 * *$ \\
\hline \multirow{3}{*}{ 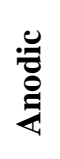 } & Electricity & 2 & 0.007 & $8435.095^{* *}$ & $0.005^{* *}$ & $0.984^{* *}$ & $0.802 * *$ & $0.1697 * *$ & $30670.685 * *$ & $0.19 * *$ & $3761.616^{* *}$ & $85.433 * *$ \\
\hline & Chelators & 3 & 0.078 & 8941.918** & $0.001^{* *}$ & $0.511^{* *}$ & $0.187 * *$ & $0.409 * *$ & $82128.007 * *$ & 0.06 & $1288.152^{* *}$ & $25.717 * *$ \\
\hline & Interaction & 6 & 0.009 & $755.552 * *$ & $\leq 0.001 * *$ & $0.020 * *$ & $0.050 * *$ & 0.012 & $19744.689 * *$ & $0.11^{* *}$ & 2394.123** & $9.922 * *$ \\
\hline
\end{tabular}

** significant at $\mathrm{P}<0.01$

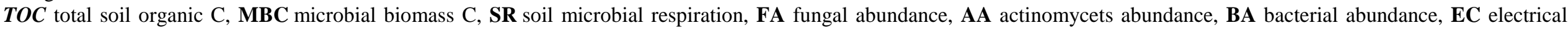
conductivity, $\boldsymbol{a v} \boldsymbol{P b}$ DTPA-extractable Pb, $\boldsymbol{a v Z n}$ DTPA-extractable Zn 
Table 3 The interaction of chelates and electric fields on soil pH in cathodic and anodic soils*

\begin{tabular}{|c|c|c|c|c|}
\hline & & $0 \mathrm{~V} / \mathrm{cm}$ & $1.1 \mathrm{~V} / \mathrm{cm}$ & $3.3 \mathrm{~V} / \mathrm{cm}$ \\
\hline \multirow{4}{*}{ نِ } & Control & $7.73^{\mathrm{cb}}( \pm 0.15)$ & $7.70^{\mathrm{cb}}( \pm 0.11)$ & $7.51^{\mathrm{cb}}( \pm 0.14)$ \\
\hline & CME & $7.37^{c}( \pm 0.40)$ & $7.72^{\mathrm{cb}}( \pm 0.09)$ & $7.86^{\mathrm{b}}( \pm 0.09)$ \\
\hline & EDTA & $7.91^{\mathrm{b}}( \pm 0.28)$ & $7.81^{\mathrm{cb}}( \pm 0.16)$ & $8.89^{\text {a }}( \pm 0.32)$ \\
\hline & $P M E$ & $7.95^{\mathrm{b}}( \pm<0.01)$ & $7.77^{\mathrm{cb}}( \pm<0.01)$ & $7.76^{\mathrm{cb}}( \pm 0.17)$ \\
\hline \multirow{4}{*}{ 暍 } & Control & $7.72^{\mathrm{ab}}( \pm 0.15)$ & $7.66^{\mathrm{ab}}( \pm 0.07)$ & $7.68^{\mathrm{ab}}( \pm 0.07)$ \\
\hline & CME & $7.37^{\text {bc }}( \pm 0.41)$ & $7.63^{\mathrm{abc}}( \pm 0.12)$ & $7.55^{\mathrm{abc}}( \pm 0.20)$ \\
\hline & EDTA & $7.91^{\mathrm{a}}( \pm 0.28)$ & $7.71^{\mathrm{ab}}( \pm 0.28)$ & $7.49^{\text {bc }}( \pm 0.29)$ \\
\hline & $P M E$ & $7.95^{\mathrm{a}}( \pm<0.01)$ & $7.65^{\mathrm{ab}}( \pm 0.06)$ & $7.23^{c}( \pm 0.05)$ \\
\hline
\end{tabular}

$\boldsymbol{C M E}$ cow manure extract, $\boldsymbol{P M E}$ poultry manure extract, $\boldsymbol{E D T A}$ Ethylenediaminetetraacetic acid Different letters show significant differences at the 0.05 probability level for each soil

*The data extracted from Tahmasbian and Safari Sinegani (2013) 
Table 4 Correlation coeffitinets between soil biological and chemical properties in cathodic and anodicc soils.

\begin{tabular}{|c|c|c|c|c|c|c|}
\hline & & $M B C$ & $S R$ & FA & $A A$ & $B A$ \\
\hline \multirow{13}{*}{ نِ } & sol-exch $\mathrm{Pb}$ & -0.08 & -0.12 & -0.21 & -0.33 & $-0.40 *$ \\
\hline & sol-exch Zn & 0.01 & -0.12 & -0.11 & -0.22 & -0.27 \\
\hline & orPb & 0.07 & 0.15 & 0.13 & 0.12 & 0.06 \\
\hline & orZn & -0.03 & 0.22 & 0.15 & 0.12 & 0.27 \\
\hline & $c r P b$ & $-0.33 * *$ & -0.24 & -0.16 & -0.15 & -0.04 \\
\hline & crZn & -0.31 & $-0.40 *$ & $-0.40 *$ & -0.15 & -0.21 \\
\hline & $t P b$ & -0.22 & $-0.44^{*}$ & $-0.54 * *$ & $-0.48 * *$ & $-0.47 * *$ \\
\hline & $t Z n$ & $-0.36^{*}$ & $-0.58 * *$ & $-0.62 * *$ & $-0.63 * *$ & $-0.54 * *$ \\
\hline & $a v P b$ & $-0.62 * *$ & $-0.57 * *$ & $-0.71 * *$ & $-0.76^{* *}$ & $-0.74 * *$ \\
\hline & $a v Z n$ & $-0.48 * *$ & -0.27 & $-0.48 * *$ & $-0.45 * *$ & $-0.39 *$ \\
\hline & $p H$ & -0.25 & $-0.42 *$ & $-0.43^{*}$ & -0.34 & $-0.51 * *$ \\
\hline & $E C$ & -0.02 & $0.41^{* *}$ & $0.45^{* *}$ & $0.41^{*}$ & 0.32 \\
\hline & TOC & 0.23 & $0.42^{* *}$ & $0.52^{* *}$ & $0.64^{* *}$ & $0.65 * *$ \\
\hline \multirow{13}{*}{ 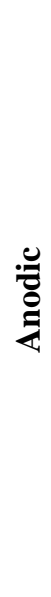 } & sol-exch $\mathrm{Pb}$ & $-0.59 * *$ & $-0.51 * *$ & $-0.76 * *$ & $-0.50 * *$ & $-0.64 * *$ \\
\hline & sol-exch Zn & $-0.76 * *$ & $-0.73 * *$ & $-0.74 * *$ & $-0.68 * *$ & $-0.77 * *$ \\
\hline & orPb & 0.24 & 0.14 & 0.1 & 0.06 & $0.37 *$ \\
\hline & orZn & 0.31 & 0.28 & 0.23 & 0.21 & $0.44 * *$ \\
\hline & $c r P b$ & $0.55^{* *}$ & $0.63^{* *}$ & $0.67 * *$ & $0.57 * *$ & $0.61 * *$ \\
\hline & crZn & $0.55^{* *}$ & $0.62 * *$ & $0.76^{* *}$ & $0.58^{* *}$ & $0.55 * *$ \\
\hline & $t P b$ & $0.56^{* *}$ & $0.55^{* *}$ & $0.64 * *$ & $0.45^{* *}$ & $0.52 * *$ \\
\hline & $t Z n$ & $0.56 * *$ & $0.50 * *$ & $0.67 * *$ & $0.49 * *$ & $0.47 * *$ \\
\hline & $a v P b$ & -0.32 & $-0.39 *$ & $-0.56 * *$ & $-0.39 *$ & -0.3 \\
\hline & $a v Z n$ & $-0.53 * *$ & $-0.69 * *$ & $-0.82 * *$ & $-0.51 * *$ & $-0.47 * *$ \\
\hline & $p H$ & 0.06 & 0.29 & 0.19 & 0.13 & -0.04 \\
\hline & $E C$ & 0.26 & $0.40 *$ & 0.19 & $0.45^{* *}$ & $0.38 *$ \\
\hline & TOC & 0.26 & 0.33 & 0.26 & 0.19 & $0.38 *$ \\
\hline
\end{tabular}

** significant at $\mathrm{P}<0.01$, * significant at $\mathrm{P}<0.05$

$\boldsymbol{M B C}$ microbial biomass carbon, $\boldsymbol{S R}$ soil respiration

$\boldsymbol{F A}$ fungal abundance, $\boldsymbol{A A}$ actinomycetes abundance, $\boldsymbol{B} \boldsymbol{A}$ bacterial abundance

sol-exch $\boldsymbol{P b}$ available $\mathrm{Pb}$, sol-exch $\mathrm{Zn}$ available $\mathrm{Zn}$, orPb Organic $\mathrm{Pb}$

orZn organic Zn, $\boldsymbol{c r} \boldsymbol{P b}$ Carbonate-bound $\mathrm{Pb}, \boldsymbol{c r Z n}$ Carbonate-bound $\mathrm{Zn}$

$\boldsymbol{t} \boldsymbol{P} \boldsymbol{b}$ total $\mathrm{Pb}, \boldsymbol{t} \boldsymbol{Z n}$ total $\mathrm{Zn}, \boldsymbol{a} \boldsymbol{\boldsymbol { P } \boldsymbol { b }}$ DTPA-extractable $\mathrm{Pb}$

$\boldsymbol{a v Z n}$ DTPA-extractable Zn

EC electrical conductivity, TOC total soil organic carbon 


\section{References}

Acar YB, Alshawabkeh AN (1993) Principles of electrokinetic remediation. Environ Sci Technol 27:2638-2647

Alcántara M, Gómez J, Pazos M, Sanromán M (2012) Electrokinetic remediation of lead and phenanthrene polluted soils. Geoderma 173:128-133

Alef K, Nannipieri P (1995) Methods in applied soil microbiology and biochemistry. London [etc.] : Academic Press,

Alkorta I, Hernández-Allica J, Becerril JM, Amezaga I, Albizu I, Onaindia M, Garbisu C (2004) Chelate-enhanced phytoremediation of soils polluted with heavy metals. Rev Environ Sci Biotech 3:55-70

Almås Å, Singh B, Salbu B (1999) Mobility of cadmium-109 and zinc-65 in soil influenced by equilibration time, temperature, and organic matter. J Environ Qual 28:1742-1750

Baath E (1989) Effects of heavy-metals in soil on microbial processes and populations (a Review). Water Air Soil Pollut 47:335-379

Baek K, Kim D-H, Park S-W, Ryu B-G, Bajargal T, Yang J-S (2009) Electrolyte conditioning-enhanced electrokinetic remediation of arsenic-contaminated mine tailing. J Hazard Mater 161:457-462

Bahemmat M, Farahbakhsh M, Shabani F (2015) Compositional and metabolic quotient analysis of heavy metal contaminated soil after electroremediation. Environ Earth Sci 74:4639-4648

Bardgett R (2005) The biology of soil: a community and ecosystem approach. Oxford University Press

Cang L, Zhou D-M, Wang Q-Y, Fan G-P (2012) Impact of electrokinetic-assisted phytoremediation of heavy metal contaminated soil on its physicochemical properties, enzymatic and microbial activities. Electrochim Acta 86:41-48

Cang L, Zhou DM, Wang QY, Wu DY (2009) Effects of electrokinetic treatment of a heavy metal contaminated soil on soil enzyme activities. J Hazard Mater 172:1602-1607

Chen M, Xu P, Zeng G, Yang C, Huang D, Zhang J (2015) Bioremediation of soils contaminated with polycyclic aromatic hydrocarbons, petroleum, pesticides, chlorophenols and heavy metals by composting: Applications, microbes and future research needs. Biotechnol Adv 33:745-755

Chirakkara RA, Reddy KR, Cameselle C (2015) Electrokinetic amendment in phytoremediation of mixed contaminated soil. Electrochim Acta 181:179-191

Choi JH, Maruthamuthu S, Lee YJ, Alshawabkeh AN (2013) Reduction of nitrate in agricultural soils by bioelectrokinetics. Soil Sediment Contam 22:767-782

Cui J-l, Luo C-l, Tang CW-y, Chan T-s, Li X-d (2017) Speciation and leaching of trace metal contaminants from e-waste contaminated soils. J Hazard Mater 329:150-158

Darby I, Xu C-Y, Wallace HM, Joseph S, Pace B, Hosseini Bai S (2016) Short-term dynamics of carbon and nitrogen using compost, compost-biochar mixture and organo-mineral biochar. Environ Sci Pollut R 23:11267-11278

Dasgupta R, Venkatesh K, Tiwari R (2016) Electrokinetic remediation of copper contaminated soils using EDTA. Int J Innov Stud Sci Engin Technol 2:18-23

de la Fuente C, Clemente R, Martínez-Alcalá I, Tortosa G, Bernal MP (2011) Impact of fresh and composted solid olive husk and their water-soluble fractions on soil heavy metal fractionation; microbial biomass and plant uptake. J Hazard Mater 186:1283-1289

Dong ZY, Huang WH, Xing DF, Zhang HF (2013) Remediation of soil co-contaminated with petroleum and heavy metals by the integration of electrokinetics and biostimulation. J Hazard Mater 260:399-408

Elzobair KA, Stromberger ME, Ippolito JA, Lentz RD (2016) Contrasting effects of biochar versus manure on soil microbial communities and enzyme activities in an Aridisol. Chemosphere 142:145-152

Epelde L, Hernández-Allica J, Becerril JM, Blanco F, Garbisu C (2008) Effects of chelates on plants and soil microbial community: Comparison of EDTA and EDDS for lead phytoextraction. Sci Total Environ 401:21-28

Facchinelli A, Sacchi E, Mallen L (2001) Multivariate statistical and GIS-based approach to identify heavy metal sources in soils. Environ pollut 114:313-324

Falciglia PP, Malarbì D, Greco V, Vagliasindi FG (2017) Surfactant and MGDA enhanced-Electrokinetic treatment for the simultaneous removal of mercury and PAHs from marine sediments. Sep Purif Technol 175:330-339

Feng D, Teng Y, Wang J, Wu J (2016) The Combined effect of Cu, Zn and Pb on enzyme activities in soil from the vicinity of a wellhead protection area. Soil Sediment Contam 25:279-295

Flessa H, Ludwig B, Heil B, Merbach W (2000) The origin of soil organic C, dissolved organic C and respiration in a long-term maize experiment in halle, Germany, determined by ${ }^{13} \mathrm{C}$ natural abundance. J Plant Nutr Soil Sci 163:157-163

Foth HD (1991) Fundamentals of soil science. vol Ed. 8. John Wiley and Sons, Inc.,

Giannis A, Nikolaou A, Pentari D, Gidarakos E (2009) Chelating agent-assisted electrokinetic removal of cadmium, lead and copper from contaminated soils. Environ Pollut 157:3379-3386

Giannis A, Pentari D, Wang J-Y, Gidarakos E (2010) Application of sequential extraction analysis to electrokinetic remediation of cadmium, nickel and zinc from contaminated soils. J Hazard Mater 184:547-554 
Guo S, Fan R, Li T, Hartog N, Li F, Yang X (2014) Synergistic effects of bioremediation and electrokinetics in the remediation of petroleum-contaminated soil. Chemosphere 109:226-233

Hosseini Bai S, Blumfield TJ, Xu Z, Chen C, Wild CH (2012) Effects of pre-planting site management on soil organic matter and microbial community functional diversity in subtropical Australia. Appl Soil Ecol 62:31-36

Hosseini Bai S, Xu Z, Blumfield TJ, Reverchon F (2015) Human footprints in urban forests: implication of nitrogen deposition for nitrogen and carbon storage. J Soils Sediments 15:1927-1936

Indoria AK, Poonia SR, Sharma KL (2013) Phytoextractability of Cd from soil by some oilseed species as affected by sewage sludge and farmyard manure. Commun Soil Sci Plant Anal 44:3444-3455

Jackman SA, Maini G, Sharman AK, Knowles CJ (1999) The effects of direct electric current on the viability and metabolism of acidophilic bacteria. Enzyme Microb Technol 24:316-324

Kandeler E, Kampichler C, Horak O (1996) Influence of heavy metals on the functional diversity of soil microbial communities. Biol Fertility Soils 23:299-306

Kim D-H, Ryu B-G, Park S-W, Seo C-I, Baek K (2009) Electrokinetic remediation of Zn and Ni-contaminated soil. J Hazard Mater 165:501-505

Kim SH, Han HY, Lee YJ, Kim CW, Yang JW (2010) Effect of electrokinetic remediation on indigenous microbial activity and community within diesel contaminated soil. Sci Total Environ 408:3162-3168

Kim SJ, Park JY, Lee YJ, Lee JY, Yang JW (2005) Application of a new electrolyte circulation method for the ex situ electrokinetic bioremediation of a laboratory-prepared pentadecane contaminated kaolinite. J Hazard Mater 118:171-176

Kovacs H, Szemmelveisz K (2017) Disposal options for polluted plants grown on heavy metal contaminated brownfield lands-A review. Chemosphere 166:8-20

Lear G, Harbottle MJ, van der Gast CJ, Jackman SA, Knowles CJ, Sills G, Thompson IP (2004) The effect of electrokinetics on soil microbial communities. Soil Biol Biochem 36:1751-1760

Lee J, Sung K (2014) Effects of chelates on soil microbial properties, plant growth and heavy metal accumulation in plants. Ecological Engineering 73:386-394

Li T, Guo S, Wu B, Li F, Niu Z (2010) Effect of electric intensity on the microbial degradation of petroleum pollutants in soil. J Environ Sci 22:1381-1386

Li T, Guo S, Wu B, Zhang L, Gao Y (2015) Effect of polarity-reversal and electrical intensity on the oil removal from soil. J Chem Technol Biotechnol 90:441-448

Li Z, Ma Z, van der Kuijp TJ, Yuan Z, Huang L (2014) A review of soil heavy metal pollution from mines in China: Pollution and health risk assessment. Sci Total Environ 468-469:843-853

Lim J-M, Salido AL, Butcher DJ (2004) Phytoremediation of lead using Indian mustard (Brassica juncea) with EDTA and electrodics. Microchem J 76:3-9

Lindsay W, Norvell W (1978) Development of a DTPA Soil Test for Zinc, Iron, Manganese, and Copper1. Soil Sci Soc Am J 42:421-428

Lu K, Yang X, Shen J, Robinson B, Huang H, Liu D, Bolan N, Pei J, Wang H (2014) Effect of bamboo and rice straw biochars on the bioavailability of $\mathrm{Cd}, \mathrm{Cu}, \mathrm{Pb}$ and $\mathrm{Zn}$ to Sedum plumbizincicola. Agric Ecosyst Environ 191:124132

Mena E, Villasenor J, Canizares P, Rodrigo MA (2011) Influence of soil texture on the electrokinetic transport of dieseldegrading microorganisms. J Environ Sci Health A Tox Hazard Subst Environ Eng 46:914-919

Mu'azu ND, Usman A, Jarrah N, Alagha O (2016) Pulsed electrokinetic removal of chromium, mercury and cadmium from contaminated mixed clay soils. Soil Sediment Contam 25:757-775

Mühlbachová G (2011) Soil microbial activities and heavy metal mobility in long-term contaminated soils after addition of EDTA and EDDS. Ecol Eng 37:1064-1071

Nguyen TTN, Xu C-Y, Tahmasbian I, Che R, Xu Z, Zhou X, Wallace HM, Bai SH (2017) Effects of biochar on soil available inorganic nitrogen: A review and meta-analysis. Geoderma 288:79-96

Nies DH (1999) Microbial heavy-metal resistance. Appl Microbiol Biotechnol 51:730-750

Pramanik P, Kim P (2013) Effect of limited nickel availability on methane emission from EDTA treated soils: Coenzyme $\mathrm{M}$ an alternative biomarker for methanogens. Chemosphere 90:873-876

Pu X, Zhang G, Zhang P, Liu Y, Zhang W (2017) Effects of straw management, inorganic fertiliser, and manure amendment on soil microbial properties, nutrient availability, and root growth in a drip-irrigated cotton field. Crop Pasture Sci 67:1297-1308

Qiao J, Sun H, Luo X, Zhang W, Mathews S, Yin X (2017) EDTA-assisted leaching of Pb and Cd from contaminated soil. Chemosphere 167:422-428

Radu AD, Panturu E, Woinaroschy A, Isopescu R (2015) Experimental design and process optimization for uranium polluted soils decontamination by acid washing. Water Air Soil Pollut 226:1-11

Rajapaksha R, Tobor-Kapłon M, Bååth E (2004) Metal toxicity affects fungal and bacterial activities in soil differently. Appl Environ Microbiol 70:2966-2973

Reddy KR, Xu CY, Chinthamreddy S (2001) Assessment of electrokinetic removal of heavy metals from soils by sequential extraction analysis. J Hazard Mater 84:279-296 
Ryu S-R, Jeon E-K, Baek K (2017) A combination of reducing and chelating agents for electrolyte conditioning in electrokinetic remediation of As-contaminated soil. J of the Taiwan Inst Chem E 70:252-259

Safari Sinegani AA, Nikbakht N, Banejad H (2016) Lead redistribution in a mine soil treated with three manures and incubated at two different temperatures. Chem Ecol 32:520-532

Safari Sinegani AA, Tahmasbian I, Safari Sinegani M (2015) Chelating Agents and Heavy Metal Phytoextraction. In: Sherameti I, Varma A (eds) Heavy Metal Contamination of Soils: Monitoring and Remediation, vol 44. Springer International Publishing, pp 367-393

Safari Singani A, Ahmadi P (2012) Manure application and cannabis cultivation influence on speciation of lead and cadmium by selective sequential extraction. Soil Sedim Contam 21:305-321

Sah JG, Che JY (1998) Study of the electrokinetic process on Cd and Pb spiked soils. J Hazard Mater 58:301-315

Song Y, Ammami M-T, Benamar A, Mezazigh S, Wang H (2016) Effect of EDTA, EDDS, NTA and citric acid on electrokinetic remediation of $\mathrm{As}, \mathrm{Cd}, \mathrm{Cr}, \mathrm{Cu}, \mathrm{Ni}, \mathrm{Pb}$ and $\mathrm{Zn}$ contaminated dredged marine sediment. Environ Sci Pollut R 23:10577-10586

Tahmasbian Ghahfarokhi I (2012) The effect of application of some chelating agents and electrical field on phytoremediation of a heavy metals polluted soil. MSc, Bu-Ali Sina University (In Perisan)

Tahmasbian I, Nasrazadani A (2012) Soil electerokinetic remediation and its effects on soil microbial activity - A review. Afr J Microbiol Res 6:2233-2238

Tahmasbian I, Nasrazadani A, Shoja H, Safari Sinegani AA (2014) The effects of human activities and different land-use on trace element pollution in urban topsoil of Isfahan (Iran). Environ Earth Sci 71:1551-1560

Tahmasbian I, Safari Sinegani AA (2013) Monitoring the effects of chelating agents and electrical fields on active forms of $\mathrm{Pb}$ and $\mathrm{Zn}$ in contaminated soil. Environ Monit Assess 185:8847-8860

Tahmasbian I, Safari Sinegani AA (2014) Chelate-assisted phytoextraction of cadmium from a mine soil by negatively charged sunflower. Int J Environ Sci Te 11:695-702

Tahmasbian I, Safari Sinegani AA (2016) Improving the efficiency of phytoremediation using electrically charged plant and chelating agents. Environ Sci Pollut R 23:2479-2486

Usman ARA, Almaroai YA, Ahmad M, Vithanage M, Ok YS (2013) Toxicity of synthetic chelators and metal availability in poultry manure amended $\mathrm{Cd}, \mathrm{Pb}$ and As contaminated agricultural soil. J Hazard Mater 262:1022-1030

Vance ED, Brookes PC, Jenkinson DS (1987) An Extraction Method for Measuring Soil Microbial Biomass-C. Soil Biol Biochem 19:703-707

Virkutyte J, Sillanpää M, Latostenmaa P (2002) Electrokinetic soil remediation—critical overview. Sci Total Environ 289:97-121

Walkley A, Black IA (1934) An examination of the Degtjareff method for determining soil organic matter, and a proposed modification of the chromic acid titration method. Soil Sci 37:29-38

Wang J, Li F, Li X, Wang X, Li X, Su Z, Zhang H, Guo S (2013) Effects of electrokinetic operation mode on removal of polycyclic aromatic hydrocarbons (PAHs), and the indigenous fungal community in PAH-contaminated soil. J Environ Sci Health A Tox Hazard Subst Environ Eng 48:1677-1684

Wang QY, Zhou DM, Cang L, Sun TR (2009) Application of bioassays to evaluate a copper contaminated soil before and after a pilot-scale electrokinetic remediation. Environ Pollut 157:410-416

Wu L, Tan C, Liu L, Zhu P, Peng C, Luo Y, Christie P (2012) Cadmium bioavailability in surface soils receiving longterm applications of inorganic fertilizers and pig manure. Geoderma 173-174:224-230

Yeung AT, Hsu CN, Menon RM (1996) EDTA-enhanced electrokinetic extraction of lead. J Geotech Eng-Asce 122:666673

Yoo J-C, Yang J-S, Jeon E-K, Baek K (2015) Enhanced-electrokinetic extraction of heavy metals from dredged harbor sediment. Environ Sci Pollut R 22:9912-9921

Zelina J, Rusling J (1998) Electrochemical remediation of soils. Encyclopedia of Environmental Analysis and Remediation 3:1567-1583

Zhang T, Zou H, Ji M, Li X, Li L, Tang T (2014) Enhanced electrokinetic remediation of lead-contaminated soil by complexing agents and approaching anodes. Environ Sci Pollut R 21:3126-3133

Zhang X, Zhang R, Gao J, Wang X, Fan F, Ma X, Yin H, Zhang C, Feng K, Deng Y (2017) Thirty-one years of rice-ricegreen manure rotations shape the rhizosphere microbial community and enrich beneficial bacteria. Soil Biol Biochem 104:208-217

Zhao Y, Yan Z, Qin J, Xiao Z (2014) Effects of long-term cattle manure application on soil properties and soil heavy metals in corn seed production in Northwest China. Environ Sci Pollut R 21:7586-759 